\title{
Developing an Approach to Colour Assessment of Works of Art on Aim to Creating a Comfortable and Harmonious Interior
}

\author{
Oksana Pylypchuk $^{1, *}$, Andrii Polubok ${ }^{1}$, Olga Krivenko², Olena Safronova ${ }^{3}$, Danylo \\ Kosenko $^{3}$, Nataliia Avdieieva ${ }^{4}$ \\ ${ }^{1}$ Department of Design, Kyiv National University of Construction and Architecture, Kyiv, Ukraine \\ ${ }^{2}$ Department of Architectural Constructions, Kyiv National University of Construction and Architecture, Kyiv, \\ Ukraine \\ ${ }^{3}$ Department of Interior and Furniture Design, Kyiv National University of Technologies and Design, Kyiv, Ukraine \\ ${ }^{4}$ Department of Architectural Design Deal, SSU KNUCA, Kyiv, Ukraine \\ "Corresponding author. Email: pylypchuk.od@knuba.edu.ua
}

\begin{abstract}
This study was specially tailored to develop an approach to colour scheme evaluation for works of art within an interior with aim to create a comfortable and harmonious living space. To achieve the study objectives, the following methods were applied: article review; systematic review of key compositional and colour links which exist between the interior and an art object; algorithmic modelling. The study has resulted in developing standards of coordinating the interior with works of art, namely: the principles of coordinating the interior colour scheme and the visual art objects; the principle of impact of lighting on perception of colour combinations present in art-objects and the interior; the principle of impact of specific surface materials on perception of colour in an art-object an interior. Based on these standards of typical colour combinations in compositional scenarios were developed and analysed, also they were applied in designing flow charts and developing an algorithmic system. The algorithm underwent preliminary testing. The obtained results are in favour of its practical application in assessing the colour of art-objects with aim to harmonising the overall colour scheme in an interior.
\end{abstract}

Keywords: Art research based on big data method, Visual arts, Colour, Interior, Design, Algorithmic process.

\section{INTRODUCTION}

The current green-home policies include not only clean energy standards but also have a variety of other environmental requirements which determine the quality of a living space. All of which has become particularly evident at the time of the COVID-19 pandemic which has significantly affected the way modern people live and work. The lockdown measures and other restrictions have insulated people from the outside world and as a result had an adverse effect on mental health.

It is well known, that appropriate use of art works within an interior helps expand and enhance the concept ideas at its base. Many experts believe that the general colour scheme applied within the interior in coordination with decorative and visual artworks helps create compositional harmony and balance, which at the subconscious level positively effects the human psyche and improves mental health [1-2]. Coordinating between interior design and visual art objects impacts the overall presentation and remains one of the most important components in creating harmony within an individual living space [3-4].

For example, architect Pieter van der Ree [5] argues that one of the key aspects in achieving balance and harmony in architecture is to identify means of association between the art work's colour scheme and the interior which is saturated in a certain emotional atmosphere and potentially affects different people in different ways. 
In this respect colour should be viewed as a practical tool which could be used to affect the human emotion and the mental state via the means of interior design which includes works of art. Taking into account that we live in a globalised and urbanised world, where rapid technological development has created demand for digital innovations and new digital tools for targeted project development it is absolutely vital to develop a practical computerised tool for colour assessment of artwork in an interior.

\section{MATERIALS AND METHODS}

The study objectives necessitate the application of the following methodological tools:

\subsection{The Article Review Method Was Applied to Formulate General Views on the Problem}

Drawing on the theoretical and practical material developed by leading scholars as well as renowned artists and art theorists the study has taken into account that in relation to any composition the unity of colour is achieved through the harmony of colour and scientific knowledge of colour systems. For the purposes of this study the methods of compositional development of colour schemes were applied as based on academic research carried out by different authors. As presented in Table 1 .

Table 1. Article Review

\begin{tabular}{|l|l|}
\hline Discussion topics in colour composition & References \\
\hline $\begin{array}{l}\text { Harmony of colour based on balanced } \\
\text { colour combinations }\end{array}$ & {$[6,7]$} \\
\hline $\begin{array}{l}\text { Colour scheme in an interior and its } \\
\text { functional purpose }\end{array}$ & {$[8,9]$} \\
\hline Laws of the contrast of colours & {$[10]$} \\
\hline $\begin{array}{l}\text { The interior colour scheme of an art form } \\
\text { under the changing light conditions }\end{array}$ & {$[11,12]$} \\
\hline Physical and optical laws of colour & {$[13]$} \\
\hline $\begin{array}{l}\text { The colour's ability to create associations, } \\
\text { re-shape and alter objects }\end{array}$ & {$[5,14]$} \\
\hline $\begin{array}{l}\text { Psychological and physiological perception } \\
\text { of colour }\end{array}$ & {$[2,9]$} \\
\hline
\end{tabular}

\subsection{Systemic analysis}

Systemic analysis of key compositional links between the colour schemes has revealed the following principles of colour harmonisation between the interior space and works of art:

The principles of correlation between the colour scheme present in the interior and the visual art objects. The process of selecting the interior's colour combination and interior design foresees selecting colours endowed with specific emotional significance and polychrome works of art incorporated into the interior depending on their size, form of art, colour dispersal, position and conditions under which they are going to be viewed, all of these should fully comply with the room's functional purpose and colour composition as defined by the creative concept. To create conditions which enhance the artistic expression of art objects and at the same time ensure balance and harmony of the entire colour milieu the research has developed an arrangement system for the art objects within an interior and examined their functional role within an interior space. As a result, the research has identified key basic principles linking the colour milieu and art objects interconnection between the art objects and the colour milieu, based on which descriptive scenarios were developed.

The principle of impact of lighting on perception of colour combinations present in art-objects and the interior. Taking into consideration that lighting is absolutely vital in interior design, systematic research produced key colour combinations to aid in the selection of the general colour scheme. These factors depend on the source of lighting and its type, e.g., direct light, reflected light, dispersed light; the light's shade of colour, e.g., warm/cold light; and the contrast level, as per tone and colour. Corresponding to the type of light descriptive scenarios were developed.

The principle of impact of specific surface materials on perception of colour in an art-object an interior. Any form's surface has particular qualities, like the quality of material: e.g., textured/non-textured, which also could be matted or polished, and semi-matted [15]. The perception of form depends on the level of contrast or colour tone/nuances, as well as the general level of saturation of the colour scheme: from dark to light. Space perception of any form and its size is determined by the saturation of colour, the distance between the coloured surface and the viewer, contrast, visual memory, and particular conditions of perception. All of these factors aid in adjusting the visual effect of space perception, its geometric volume, activate or annihilate altogether the visual perception of form, and completely re-shape the visual perception of the interior.

Systematic analysis has produced basic descriptive scenarios for in respect to harmonising the colour scheme of the interior and art objects. Description of developed scenarios for colour combinations is presented in flow charts under the Algorithmic Action Stage II (see C).

\subsection{The algorithmic modelling method}

The algorithmic modelling method was used to create an algorithm based on flow diagrams as per the ISO Standard [16]. The algorithmic process consists of three stages, which incorporate valid/invalid combinations of input data, based on linked logical sequences of action. The algorithm uses flow charts to search for relevant compositional scenarios; these reflect logically structured models which contain coded 
scenarios pulled from the existing data bank (compositional colour schemes). The algorithm of balancing art work and the interior colour scheme is presented in Fig. 3a-c.

Algorithmic Action Stage I: rational selection. Scenario selection as per corresponding creative concept. Selection of the interior colour scheme should correspond to the interior's functional purpose, i.e., standard project requirements like commercial/residential property; the room's geometric dimensions as well as the emotional impact the interior space creates at the time of perception, i.e., positive, negative or neutral Fig. 1.

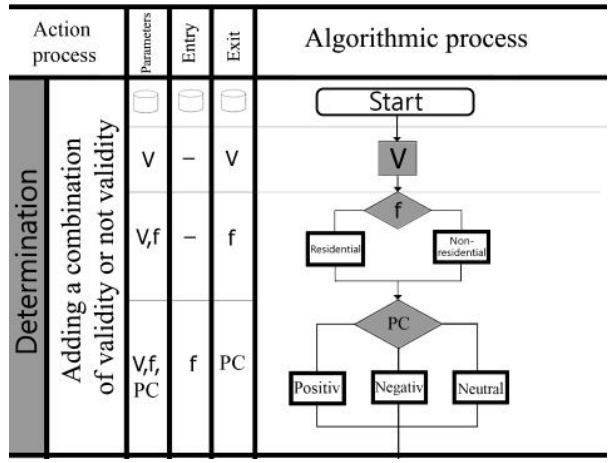

Figure 1 Start of the algorithmic action. The Algorithmic Action Rational Selection Stage.

Algorithmic Action Stage II: the creative variant selection stage. It was designed to outline the means of selecting harmonious colour combinations which help create compositional and colour unity in an interior space with art objects. The process involves compilation action coupled with creative selection and developing each scenario depending on the course of the algorithm. This Stage allows for change in the parameters used for combinations and modifications in various compositional scenarios; and which are joined based on both specific characteristics and general qualities. At each stage further selection depends on the previous combination results which are defined as valid or invalid Fig. 2.

\section{Key to Fig. 1, 2:}

V - interior's overall geometric dimensions; PC perception criteria under which the visual art objects are perceived in the colour milieu of the interior; IC\&AO harmonisation between the colour scheme of the interior and art objects; CS - general level of saturation of colour; Lt - light tones and Dk - dark tones; Rf - reflected colour and light. Source of light: Dr - direct light; Rtd reflected light; Ds - dispersed light; W - warm and C cold light hues; cs - contrast and $\mathrm{n}$ - nuance. The level of contrast: c -colour and $\mathrm{t}$ - tone; $\mathrm{AO}$ - art objects; Int Interior; $\mathrm{C}$ - interconnection between the art objects and the colour milieu; $\mathrm{Cs}$ - colour solution based on contrast, $\mathrm{n}$ - based on nuance; Adj - polychrome's ability for adjustment; tx - textured and n/tx - non-textured material; $\mathrm{m}$ - matted, $\mathrm{p}$ - polished and $\mathrm{s} / \mathrm{m}$ - semi-matted textures.

Stage III - the result of algorithmic analysis. Processing of data (automatic testing and optimal variant selection). The process is reliant on correspondence to the creative concept (Stage I of algorithmic action) and the sequence of input/output parameters and leads to a positive result $[1(+)]$, which signals the end of algorithmic action. In case of a negative result [1(-)] or unspecified result [0] the algorithmic process returns to the beginning of creative stage of algorithmic action.

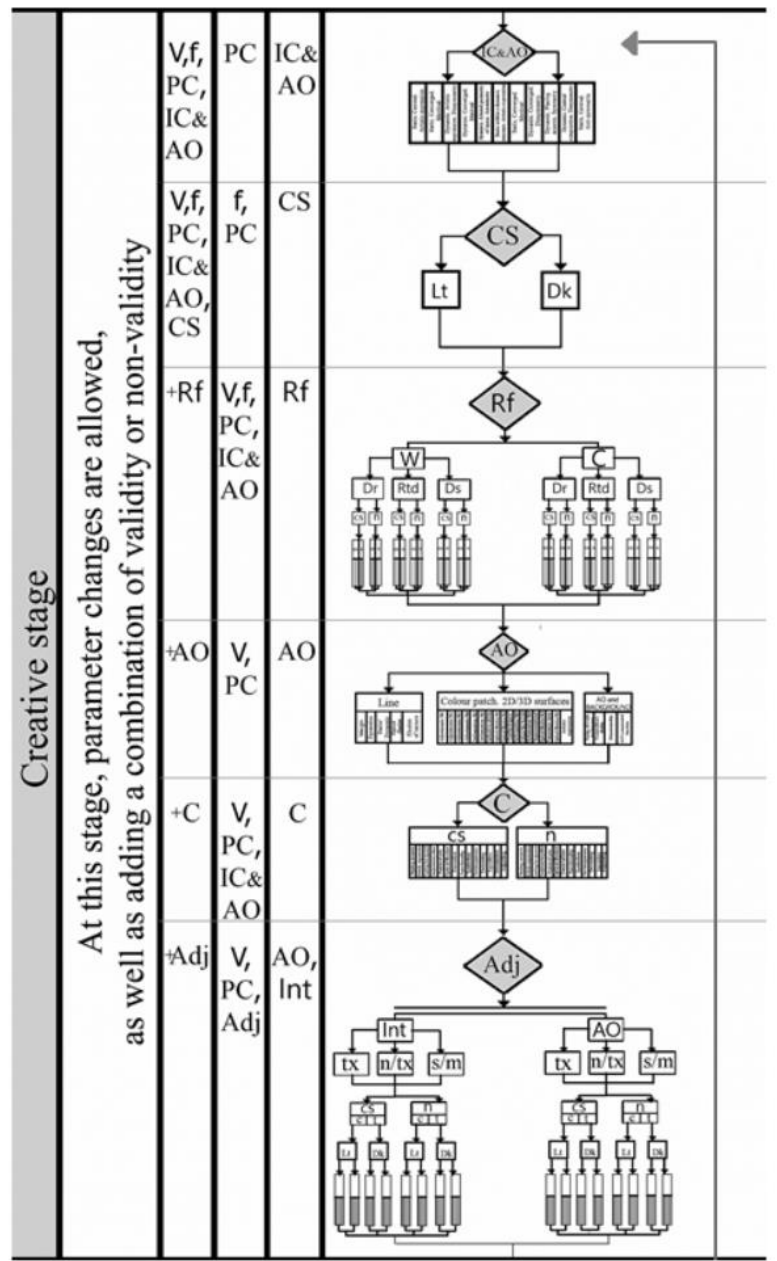

Figure 2 Algorithmic action continues. Creative choice stage. 


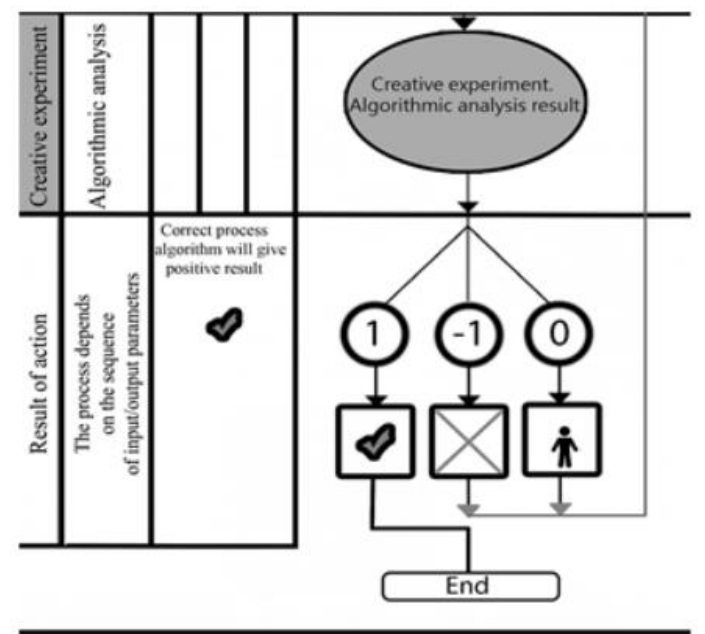

Figure 3 Algorithm's results and analysis. Algorithmic action has run its course.

It should be noted that the negative reaction result could still be applied under the creative process but it does not correspond to the requirements of invariant selection and per a specific creative concept Fig. 3.

It should be noted that the negative reaction result could still be applied under the creative process but it

Table 2. Examples of Obtained Colour Solutions Produced as a Result of Algorithmic Action Which Corresponds to the Creative Concept

\begin{tabular}{|c|c|c|c|}
\hline \multicolumn{4}{|c|}{ Result of algorithmic action } \\
\hline Basic source & $\begin{array}{l}\text { Balanced colour } \\
\text { scheme. Corresponds to the creative } \\
\text { concept requirements } \\
{[1(+)]}\end{array}$ & $\begin{array}{c}\text { Colour scheme does not } \\
\text { correspond } \\
\text { to the creative concept } \\
{[1(-)]}\end{array}$ & $\begin{array}{c}\text { The colour scheme is out of } \\
\text { balance, project } \\
\text { in need } \\
\text { of revision }\end{array}$ \\
\hline $\begin{array}{l}\text { 1. Residential interior } \\
\text { - Sitting room }\end{array}$ & (a) & (b) & (c) \\
\hline $\begin{array}{l}\text { 2. Public dining } \\
\text { interior - Cafe }\end{array}$ & (a) & (b) & (c) \\
\hline $\begin{array}{l}\text { Commercial } \\
\text { 3.Comm } \\
\text { interior - Beauty } \\
\text { parlour }\end{array}$ & $\begin{array}{l}2+0 \\
i\end{array}$ & (b) & $\frac{1}{2}$ \\
\hline
\end{tabular}

Images 1-3 reflect on the link between the colour scheme and different end results of the algorithmic process. The parameters of generated design ideas correspond to the following criteria defined by the creative concept: does not correspond to the requirements of invariant selection and per a specific creative concept.

\section{PROJECT DEVELOPMENT FOR HARMONISING THE INTERIOR COLOUR SCHEME AND VISUAL ART OBJECTS}

In order to test the accuracy of the developed practical tool and provide recommendations on its implementation a test assignment for different types of the interior was performed, e.g., commercial/residential premises; it was planned for the analysis process to include a sufficient number of scenarios and requirements to the creative concept. With this purpose in mind a basic interior design project in need of colour review was selected (a real project). A following objective was set: to harmonise the colour composition of an art work with the interior in respect to the creative concept criteria, e.g., type of premises and function, emotional impact at the time of perception. Each colour combination was assessed based on the generated standards.

Key examples of results generated in the process of algorithm testing are presented in Table 2 .

Emotionally calm atmosphere. The room is cosy, the mood is pleasant, and uplifting: (a) - balance of warm colours corresponds to scenario "Static. Centred. Artistic expression", the art object is flat - scenario "Fusing AO with background", in respect to the interior the scenario corresponds to "Creating a compositional centre"; (b) - 
the use of lighting creates a welcoming atmosphere, the light source is dispersed, with a warm hue, and there is a nuanced balance with the general colour scheme; (c) the room did not require any major adjustments in relation to its geometric shape, the selected surface textures are matt (the warm harmony of colour nuanced by colours and hues from the darker colour spectrum).

The mood is positive; atmosphere is relaxing: (a) harmony of warm colours corresponds to scenario "Dynamic Artistic expression. Dissymmetry", the art object is flat "AO's ornamental function" scenario, in respect to the interior the scenario corresponds to "Decorating"; (b) - objects within the Interior require natural lighting, the source of lighting is direct, with a cold hue and in contrast with the general colour scheme; (c) - the adjustment of space volume was supposed to create an illusion of a broken space, matt textures were used (warm harmony of colour contrasted by colours and hues from the darker colour spectrum).

The positive mood is aimed at supporting work efficiency: (a) - the harmony of cold colours corresponds to scenario "Static. Converged. Identical", the art object is three-dimensional and corresponds to scenario "Fusing AO with background", in respect to the interior the scenario corresponds to "Complementary effect"; (b) - the premises require maximum visibility, the source of lighting is dispersed, with cold hues, nuanced by the general colour scheme; (c) - the adjustment of space volume was supposed to create an illusion of extended space, the surface textures are glazed (cold colour scheme nuanced by colours and hues from the lighter colour spectrum).

\section{DISCUSSION}

Modern technologies offer different approaches to creating comfortable living conditions and maintaining a good level of mental health within a living space. For example, theoretical methodologies based on the guidelines for arranging polychrome works of art , which are in general determined by the interior's style as well as the interior's atmosphere [1,17]; ecological and ergonomic aspects of environmental design $[18,19]$; the essential links between the environment, its functional purpose and physiological comfort, labour efficiency as well as supporting and creating mental harmony $[4,8$, 20]; developing progressive and functionally useful mobile gadgets designed to improve human comfort [21, 22]. Currently there is the WELL certification standard, which is one of the first leading tools for advancing health and well-being in buildings globally [23]. The WELL standard promotes introduction of works of art and application of "aesthetically appealing design" to reduce stress levels and promote overall health of occupants in buildings. Studying the artistic legacy has brought us closer to understanding the nature of colour in works of art and its association with the environment.
However, unfortunately it is supported exclusively by finalised real projects, is intuitive in nature and is based exclusively on emotional, sensuous, and practical experience. Notably, all modern designers and artists when tackling the practical aspect of choosing a colour scheme for a work of art, which will be incorporated into an interior usually rely on their personal emotional experience and associative thinking as well as professional and creative experience, intuition and professional artistic taste. Often we are able to view the complete result of implemented projects presented in leading architectural magazines. Unfortunately, theoretical discussion between researchers on the subject of finding balance between works of art and the interior colour solutions usually does not go beyond implemented projects and as a result one cannot identify scientific and theoretical principles which guided this practical activity; thus the logic applied to achieving the desired effect remains elusive.

Today's scientists believe that the development of artificial intelligence and commuter learning based on computational aesthetics as well as developing neuron algorithms will drastically change our daily lives [24, 25]. The same goes for problems associated with the field of visual arts and the creative process in general these could be resolved with aid of artificial intelligence, which will considerably aid in understanding the artistic legacy of artists and designers of the 21st century [26], including the visual approaches used by artists in different historical periods $[27,28]$. The newly available computerised tools designed to assess beauty and create aesthetically pleasing objects are being investigated in the framework of computational aesthetics, an emerging interdisciplinary field of inquiry which functions at the fringes of science and art. However, there are no practical tools available or comprehensive studies which could assess colour combinations in works of art incorporated into an interior and which could be applied to harmonise a living space.

In this respect colour should be viewed as a practical tool which could be used to affect the human emotion and the mental state via the means of interior design which includes works of art. Taking into account that we live in a globalised and urbanised world, where rapid technological development has created demand for digital innovations and new digital tools for targeted project development it is absolutely vital to develop a practical computerised tool for colour assessment of artwork in an interior. Accordingly, the innovative design approach proposed in the article is promising.

\section{CONCLUSIONS}

The following study objectives have been fulfilled:

The study has identified key compositional links between colour solutions to objects of art and the interior. 
A linear process algorithm for achieving a balance between the colour scheme of the interior and the works of art has been developed.

The improved algorithm could be applied as a practical tool in project development with application of data mining technology.

The study plans to maintain and further analyse generated ideas; it also plans to expand and refine the data bank for compositional colour schemes. Our research results on formalising creative activity have identified a logical and practical model which could substitute the intuitive trial-and-error approach to evaluating art works in respect to colour in an interior space.

\section{REFERENCES}

[1] Q. Wang, "Analysis of Interior Space Design and Visual Artistic Effect", J. CSP, pp. 362-366, November 2018 [The 1st Inter. Conf. on Education Art Management and Soc. Sciences, Malaysia, p. 524, 2018].

[2] K. Yildirima, A. Akalin-Baskayab, M.L. Hidayetoglu, "Effects of indoor color on mood and cognitive performance", J. Building and Environment, vol. 42(9), pp. 3233-3240, September 2007.

[3] L. Lankston, P. Cusack, C. Fremantle, C. Isles, "Visual art in hospitals: case studies and review of the evidence", J. of the Royal Society of Medicine, vol. 103(12), pp. 490-499, December 2010.

[4] Pilipchuk, Y. Kolomiiets, "Elaboration of main methods of using coloristics at creating the ecological interior space including artworcs", J. EUREKA: Art and Hum., vol. 3, pp. 3-8, March 2019.

[5] P. Van der Ree, "Organische Architektur". Stuttgart: Verlag Freies Cestesleben, 2001, p. 247.

[6] Itten, "Kunst der Farbe". Rawensburg, 1981, p. 236.

[7] Nemcsics, J. Takacs, "Experimental Determination of Laws of Color Harmony Part 8: Harmony Content Versus Relative Surface Coverage", J. Color Research \& Application, vol. 39(4), pp. 387 398, August 2014.

[8] D. Shin, J. Kim, "A Study on the Color Characteristics Applied to Waldorf School Classroom in Healing Views", J. Archives of Design Research, vol. 31(1), pp. 149-159, February 2018.

[9] Ulusoy, N. Olgunturk, R. Aslanoglu, "Pairing colours in residential architecture for different interior types", J. Color Res Appl., Wiley, vol. 46, pp. 1079-1090, March 2021.

[10] M. Long, I. Moore, F. Mollica, P. RubioFernandez, "Contrast perception as a visual heuristic in the formulation of referential expressions", J. Cognition, vol. 217(104879), pp. 114, August 2021.

[11] R.W. Pridmore, "Preferred illumination for paintings: Cool-warm balanced colour temperature predicted from radiometry and colorimetry", J. Lighting Research \& Technolog, SAGE, vol. 0, pp. 1-14, March 2016.

[12] J. Jung, K. Cho, S. Kim, C. Kim, "Exploring the Effects of Contextual Factors on Home Lighting Experience", J. Archives of Design Research, vol. 31(1), pp. 5-21, February 2018.

[13] N. Savavibool, C. Moorapun, "Effects of Colour, Area, and Height on Space Perception", J. Environment-Behaviour Proceedings, vol. 2(6), pp. 351-359, October 2017 [Inter. Conf. on Quality of Life "Quality of Life 3", Malaysia, p. 404, 2017].

[14] M.J.P. Van Zuijlen, S.C. Pont, M.W.A. Wijntjes, "Painterly depiction of material properties", J. of Vision, vol. 20, pp. 1-17, July 2020.

[15] Pylypchuk, O. Krivenko, A. Polubok, A. Zapryvoda, V. Zapryvoda, "Ecological Innovations of Materials in Art Objects to Create a Comfortable Human Environment", J. Advances in Soc. Science, Education and Human., vol. 568, pp. 1-6, July 2021 [The 2nd Inter. Conf. on Modern Education Management, Innovation and Entrepreneurship and Soc. Science, China, p. 261, 2021].

[16] ISO 5807:1985.

URL: https://www.iso.org/standard/11955.html [Retrieved June 25, 2021].

[17] J. Pila, I.A. Gura, "Histori of interior design", Canada: Wiley, 2014, p. 496.

[18] M. Nan, H-W. Chau, J. Zhou, M. Noguchi, "Structuring the Environmental Experience Design Research Framework through Selected Aged Care Facility Data Analyses in Victoria", J. Sustainability, vol. 9(12):2172, pp. 173-193, November 2017.

[19] Nazrin, A. Anuar, S. Selamat, N. Jaini, N.I Hashim, "The Evaluation of Interior Design Elements in Nature Interpretation Centre", J. of Hotel and Business Management, vol. 8(191), pp. 1-10, January 2019.

[20] M.A. Rouaa, "The Effects of the Physical Environment Design on Teachers' Workplace 
Comfort: A Critical Review", the International J. of Architectonic, Spatial, and Environmental Design, pp. 17-30, September 2020.

[21] M. Banaeia, A. Ahmadib, K. Gramanncde, J. Hatamif, "Emotional evaluation of architectural interior forms based on personality differences using virtual reality Author links open overlay panel", J. Frontiers of Architectural Research, vol. 9(1), pp. 138-147, March 2020.

[22] P. Jayathissa, M. Quintana, M. Abdelrahman, C. Miller, "Humans - as - a - Sensor for Buildings Intensive Longitudinal Indoor Comfort Models", J. Buildings, vol. 10(10) 174, pp. 4-22, October 2020.

[23] Building Standard WELL 2021, URL: https://www.wellcertified.com [Retrieved June 25, 2021].

[24] Y. Bo, J. Yu, K. Zhang, "Computational aesthetics and applications. Visual Computing for Industry", J. Visual Computing for Industry, Biomedicine, and Art, vol. 1(1):6, pp. 2-19, September 2018.

[25] J-W. Hong, N.M. Curran, “Artificial Intelligence, Artists, and Art: Attitudes Toward Artwork Produced by Humans vs. Artificial Intelligence", J. ACM Transactions on Multimedia Computing, Communications, and Applications, vol. 15(2), pp. 1-16, August 2019.

[26] M. Mazzone, A. Elgammal, “Art, Creativity, and the Potential of Artificial Intelligence", J. Arts, vol. 8(1), pp. 2-9, February 2019.

[27] G. Castellano, G. Vessio, “Deep learning approaches to pattern extraction and recognition in paintings and drawings: an overview", J. Neural Computing and Applications, vol. 1583, pp. 1-20, April 2021.

[28] H. Lin, M. Van Zuijlen, M.W.A. Wijntjes, S.C. Pont, K. Bala, "Insights From A Large-Scale Database of Material Depictions In Paintings", J. Springer, Cham, vol. 12663, pp. 531-545, January 2021 [Inter. Conf. on Pattern Recognition, p. 767, Virtual Event, 2021]. 